\title{
PENGGUNAAN BEBAT PERINEUM (KEMPITAN) UNTUK MENGURANGI NYERI LUKA PERINEUM PADA IBU POST PARTUM
}

\author{
Dewi Susilowati, Triwik Sri Mulati \\ Kementerian Kesehatan Politeknik Kesehatan Surakarta Jurusan Kebidanan
}

\begin{abstract}
Perineal Bandage, Maternal Perineal Wound Pain. The purpose of this study to prove the effect of perineal bandage to reduce pain in the perineal wound. The research design was quasi experiment with untreated control group design with pretest and posttest samples: some post partum mother who suffered wounds perineum in BPM Klaten some 91 people. Bivariate data analysis using statistical test used is $t$-test. Results from this study is that the bandage perineum (kempitan) is effective for reducing maternal perineal wound pain post partum compared to the control group who were given regular perineal wound treatment but without being given a dressing perineum.
\end{abstract}

Keyword: Perineal Bandage, Maternal Perineal Wound Pain

\begin{abstract}
Abstrak: Bebat Perineum, Ibu Post Partum, Nyeri Luka Perineum. Tujuan penelitian ini untuk membuktikan pengaruh penggunaan bebat perineum untuk mengurangi rasa nyeri pada luka perineum. Desain penelitian ini adalah quasi eksperiment dengan untreated control group design with pretest and posttest Sampel : sebagian Ibu post partum yang mengalami luka perineum di BPM wilayah Klaten sejumlah 91 orang. Analisis data bivariat menggunakan Uji statistika yang digunakan yaitu $\mathrm{t}$ - test .Hasil dari penelitian ini adalah bahwa bebat perineum (kempitan) cukup efektif untuk mengurangi nyeri luka perineum pada ibu post partum di bandingkan pada kelompok kontrol yang diberi penanganan luka perineum biasa tapi tanpa diberi bebat perineum
\end{abstract}

Kata Kunci: Bebat Perineum, Ibu Post Partum, Nyeri Luka Perineum

\section{PENDAHULUAN}

Persalinan adalah suatu proses

keluarnya hasil konsepsi ( bayi) yang dapat hidup Dari dalam uterus ke dunia luar. Pada proses pengeluaran bayi sering terjadi perlukaan pada jalan lahir atau luka perineum (Mochtar, 2008)

Luka Perineum secara alami disebut ruptur, dikarenakan adanya desakan kepala janin yang terlalu cepat atau bahu pada proses persalinan yang lukanya tidak teratur dan luka perineum yang di sengaja di episiotomi untuk memperbesar muara vagina pada saat perineum dan vagina meregang sebelum keluar kepala bayi (Suherni, 2009).

Penanganan luka perineum dilakukan dengan melihat derajat luka, untuk derajat I jika tidak ada perdarahan tidak diperlukan penjahitan, derajat II IV dilakukan penjahitan (Wiknjosatro, 2008)

Luka pada perineum biasanya ringan, akan tetapi kadang-kadang terjadi luka yang luas dan berbahaya. ibu nifas akan mengalami keluhan nyeri pada perineum akibat luka jahitan peradangan ataupun bengkak dan lecet pada vagina. 
Peradangan adalah suatu reaksi yang normal dan merupakan hal penting untuk memastikan penyembuhan luka dan berfungsi mengisolasi jaringan rusak dan mengurangi penyebaran infeksi (Suleha, 2009)

Luka perineum akan menyebabkan nyeri dan rasa tidak nyaman pada ibu postpartum, hal ini akan mengganggu interaksi ibu dan bayi, membuat ibu lebih rentan terkena infeksi dan terjadi perdarahan jika luka perineum tidak dipantau dengan baik.

Nyeri perineum akan menimbulkan dan mempengaruhi kesejahteraan perempuan secara fisik, psikologis dan sosial pada periode postnatal langsung maupun dalam jangka panjang (Mochtar, 2008)

Dengan adanya nyeri dan bengkak pada perineum membuat ibu takut untuk mobilisasi dini, sedangkan manfaat mobilisasi dini adalah: melancarkan pengeluaran lokea, mengurangi infeksi, mempercepat involusio alat kandungan, melancarkan peredaran darah, mencegah tromboplebitis dan akan mempercepat penyembuhan luka. Untuk mengatasi hal ini maka ibu post partum diberikanan bebat perineum (kempitan) untuk mengurangi rasa nyeri dan bengkak, sehingga ibu post partum bisa melakukan mobilisasi dini.

Bebat perineum (kempitan) adalah balutan pada perineum yang diberikan setelah menggunakan pembalut dan celana dalam untuk mengurangi nyeri dan pembengkakan.

Manfaat bebat pada luka antara lain: mengurangi nyeri, mengurangi bengkak, mengurangi ketegangan jaringan luka dan mendukung bagian otot yang terluka supaya menyatu kembali.
Tujuan dari penelitian ini adalah membuktikan pengaruh penggunaan bebat perineum untuk mengurangi rasa nyeri pada luka perineum. Hipotesisi penelitian ini adalah ada pengaruh penggunaan bebat perineum (kempitan) untuk mengurangi nyeri pada luka jahitan perineum.

\section{METODE PENELITIAN}

Desain penelitian ini adalah quasi eksperiment dengan pretest and posttest with control group design

Sampel dalam penelitian ini adalah ibu post partum yang mengalami luka perineum tapi yang tidak ada kompikasi sejumlah 91 orang, yaitu kelompok kontrol (diberi penanganan luka biasa tapi tanpa di beri bebat perineum) sejumlah 43 orang dan kelompok perlakuan (diberi penanganan luka biasa dan diberi bebat perineum) sejumlah 48 orang.

Instrument dalam penelitian ini adalah lembar observasi untuk mencatat bentuk dan derajat luka perineum

Analisis data dilakukan dengan menggunakan uji t-test.

\section{HASIL PENELITIAN}

Hasil penelitian dapat dideskripsikan sebagai berikut:

Tabel 1

Distribusi Frekuensi Rentang Nyeri Luka Perineum (Pre Test) Pada Kelompok Perlakuan

\begin{tabular}{cccc}
\hline & Kategori & $\mathbf{N}$ & $\mathbf{\%}$ \\
\hline 1. & Tidak nyeri & 1 & 2.1 \\
2. & Nyeri ringan & 22 & 45.9 \\
3. & Nyeri sedang & 8 & 16.7 \\
4. & Nyeri berat & 17 & 35.3 \\
\hline & Total & 48 & 100 \\
\hline
\end{tabular}


Berdasarkan tabel 1 terlihat bahwa rentang nyeri luka perineum ibu nifas sebelum diberi bebat perineum (kempitan) mayoritas adalah nyeri ringan yaitu sebanyak 22 responden (45.9\%).

\section{Tabel 2}

Distribusi Frekuensi Rentang Nyeri Luka Perineum (Post Test 1) Pada Kelompok Perlakuan

\begin{tabular}{llcc}
\hline & Kategori & $\mathbf{n}$ & $\mathbf{\%}$ \\
\hline 1. & Tidak nyeri & 7 & 14.6 \\
2. & $\begin{array}{l}\text { Nyeri } \\
\text { ringan }\end{array}$ & 29 & 60.3 \\
3. & $\begin{array}{l}\text { Nyeri } \\
\text { sedang }\end{array}$ & 11 & 23 \\
4. & Nyeri berat & 1 & 2.1 \\
\hline & \multicolumn{1}{c}{ Total } & 48 & 100
\end{tabular}

Berdasarkan tabel 2. dapat dilihat bahwa rentang nyeri luka perineum ibu nifas setelah diberi bebat perineum (kempitan) selama satu hari (post test 1) mayoritas adalah nyeri ringan yaitu sebanyak 29 responden $(60.3 \%)$.

\section{Tabel 3}

Distribusi Frekuensi Rentang Nyeri Luka Perineum (Post Test 2) Pada Kelompok Perlakuan

\begin{tabular}{lcc}
\hline \multicolumn{1}{c}{ Kategori } & $\mathbf{N}$ & $\mathbf{P}$ \\
\hline 1. Tidak nyeri & 30 & 62.4 \\
2. Nyeri ringan & 17 & 35.5 \\
3. Nyeri sedang & 1 & 2.1 \\
4. Nyeri berat & - & - \\
\hline \multicolumn{1}{c}{ Total } & 48 & 100 \\
\hline
\end{tabular}

Berdasarkan tabel 3. dapat dilihat bahwa rentang nyeri luka perineum ibu nifas setelah diberi bebat perineum (kempitan) selama tiga hari (post test 2) mayoritas adalah tidak nyeri yaitu sebanyak 30 responden (62.4\%).
Tabel 4

Distribusi Frekuensi Rentang Nyeri Luka Perineum (Pre Test) Pada Kelompok Kontrol

\begin{tabular}{lcc}
\hline \multicolumn{1}{c}{ Kategori } & N & Prosentase \\
\hline 1. Tidak nyeri & 1 & 2.3 \\
2. Nyeri ringan & 18 & 41.9 \\
3. Nyeri sedang & 12 & 27.9 \\
4. Nyeri berat & 12 & 27.9 \\
\hline \multicolumn{1}{c}{ Total } & 43 & 100 \\
\hline
\end{tabular}

Berdasarkan tabel 4 terlihat bahwa rentang nyeri luka perineum ibu nifas pre test pada kelompok kontol mayoritas adalah nyeri ringan yaitu sebanyak 18 responden $(41.9 \%)$.

\section{Tabel 5}

Distribusi Frekuensi Rentang Nyeri Luka Perineum (Post Test 1) Pada Kelompok Kontrol

\begin{tabular}{llcc}
\hline & Kategori & $\mathbf{N}$ & Prosentase \\
\hline 1. & Tidak nyeri & 8.9 & 11.6 \\
2. & $\begin{array}{l}\text { Nyeri } \\
\text { ringan }\end{array}$ & 20 & 46.5 \\
3. & $\begin{array}{l}\text { Nyeri } \\
\text { sedang }\end{array}$ & 16 & 37.2 \\
4. & Nyeri berat & 2 & 4.6 \\
\hline & \multicolumn{1}{c}{ Total } & 43 & 100 \\
\hline
\end{tabular}

Berdasarkan tabel 5. dapat dilihat bahwa rentang nyeri luka perineum ibu nifas post test 1 pada kelompok kontrol mayoritas adalah nyeri ringan yaitu sebanyak 20 responden $(46.5 \%)$.

Tabel 6

Distribusi Frekuensi Rentang Nyeri

Luka Perineum (Post Test 2) Pada Kelompok Kontrol

\begin{tabular}{llcc}
\hline & Kategori & $\mathbf{N}$ & $\mathbf{\%}$ \\
\hline 1. & Tidak nyeri & 30 & 62.5 \\
2. & $\begin{array}{l}\text { Nyeri } \\
\text { ringan }\end{array}$ & 17 & 35.4 \\
3. & $\begin{array}{l}\text { Nyeri } \\
\text { sedang }\end{array}$ & 1 & 2.1 \\
4. & Nyeri berat & - & - \\
\hline & Total & 48 & 100 \\
\hline
\end{tabular}


Berdasarkan tabel 6. dapat dilihat bahwa rentang nyeri luka perineum ibu nifas post test 2 pada kelompok kontrol mayoritas adalah tidak nyeri yaitu sebanyak 30 responden $(62.5 \%)$.

3. Hasil uji Statistik pada Penggunaan Bebat Perineum (Kempitan) untuk Mengurangi Nyeri Luka Perineum Pada Ibu Post partum

Tabel 7

Hasil Statistik Penggunaan Bebat Perineum (Kempitan) Untuk Mengurangi Nyeri Luka Perineum Pada Ibu Post Partum Pada Kelompok Perlakuan

\begin{tabular}{|c|c|c|c|}
\hline Nyeri Perineum & $\mathbf{N}$ & Mean & SD \\
\hline Pre test & 48 & 4.77 & 2.6 \\
\hline Post test 1 & 48 & 2.75 & 1.8 \\
\hline Post test 2 & 48 & 0.58 & 1.1 \\
\hline
\end{tabular}

diketahui bahwa nilai rata rata nyeri luka perineum pada ibu nifas sebelum di beri bebat perineum (pre test) adalah 4.77, nilai rata rata nyeri luka perineum pada ibu nifas setelah di beri bebat perineum selama 1 hari (post test 1 ) adalah 2.75 dan setelah di beri bebat perineum selama 3 hari (post test ke 2) adalah 0.58 .

\section{Tabel 8}

Hasil Statistik Penggunaan Bebat Perineum (Kempitan) untuk

Mengurangi Nyeri Luka Perineum Pada Ibu Post partum pada Kelompok Kontrol

\begin{tabular}{lccc}
\hline Nyeri Perineum & N & Mean & SD \\
\hline Pre test & 43 & 4.53 & 2.5 \\
Post test 1 & 43 & 3.33 & 2.2 \\
Post test 2 & 43 & 1.93 & 1.7 \\
\hline \multicolumn{1}{c}{ Berdasarkan } & tabel & 8. & dapat
\end{tabular}

diketahui bahwa nilai rata rata nyeri luka perineum pada ibu nifas pre tes pada kelompok kontrol adalah 4.53, nilai rata rata nyeri luka perineum pada ibu nifas post test 1 pada kelompok kontrol adalah 3.33 dan rata rata nyeri luka perineum pada ibu nifas post test ke 2 pada kelompok kontrol adalah 1.93.

Hasil uji normalitas data menggunakan uji Shapiro Wilk, menunjukkan bahwa nilai Asymp.Sig (2tailed) $=0.001$ yang berarti data berdistribusi tidak normal sehingga pengolahan data menggunakan uji statistik nonparametrik, yaitu uji Wilcoxon.

\section{Hasil Uji Wilxocon terhadap Data Penelitian Kelompok Perlakuan Pre test dan Post test 1.}

Untuk mengetahui beda rerata antara rentang nyeri perineum pada ibu nifas sebelum dan setelah diberi bebat perineum selama satu hari (Post tes 1) maka dilakukan uji Wilcoxon. Hasil uji Wilcoxon menunjukkan $\mathrm{p}$ value $=0.001$, dimana $\mathrm{p}<0.05$ yang berarti ada perbedaan yang signifikan antara rentang nyeri perineum ibu nifas sebelum di beri pembebatan dengan setelah diberi satu hari pembebatan.

\section{Hasil Uji Wilxocon terhadap Data Penelitian kelompok Perlakuan Post tes 1 dan Post tes 2.}

Untuk mengetahui beda rerata antara rentang nyeri perineum pada ibu nifas setelah diberi bebat perineum selama satu hari (Post test 1) dan setelah diberi bebat perineum selama tiga hari (Post test 2) maka dilakukan uji Wilcoxon. Hasil uji Wilcoxon menunjukkan $\mathrm{p}$ value $=0.001$, dimana $\mathrm{p}<0.05$ yang berarti ada perbedaan yang signifikan antara rentang nyeri perineum ibu nifas setelah diberi bebat perineum selama satu hari dengan setelah diberi tiga hari pembebatan. 


\section{Hasil Uji Data Penelitian Kelompok Kontrol dengan kelompok Perlakuan.}

Untuk mengetahui beda rerata antara rentang nyeri perineum kelompok kontrol dengan kelompok perlakuan dilakukan penghitungan mean yang dipresentasikan pada tabel berikut:

\section{Tabel 9}

\begin{tabular}{|c|c|c|c|}
\hline $\begin{array}{r}\text { Hasil S } \\
\text { Perin } \\
\text { Mengur } \\
\text { ada Ibu } \\
\text { Kontrol }\end{array}$ & $\begin{array}{l}\text { atistik I } \\
\text { eum (K } \\
\text { angi Ny } \\
\text { ost Par } \\
\text { Dan Ke }\end{array}$ & $\begin{array}{l}\text { engguna } \\
\text { empitan) } \\
\text { eri Luka } \\
\text { tum Pada } \\
\text { lompok Pat }\end{array}$ & $\begin{array}{l}\text { Bebat } \\
\text { tuk } \\
\text { ineum } \\
\text { lompok } \\
\text { akuan }\end{array}$ \\
\hline yeri & Mean & Mean & Selisih \\
\hline Perineum & Kontrol & Perlakuan & Mean \\
\hline e test & 4.53 & 4.77 & -0.24 \\
\hline Post test 1 & 3.33 & 2.75 & 0.58 \\
\hline ost test & 1.93 & 0.58 & 1.35 \\
\hline
\end{tabular}

Pada tabel 9. dapat dilihat bahwa pada data Pre test, rata rata rentang nyeri kelompok perlakuan lebih tinggi 0.24 dibandingkan kelompok kontrol. Tetapi setelah kelompok perlakuan diberi pembebatan perineum selama 1 hari (Post test 1) maka rata rata rentang nyeri perineum kelompok perlakuan lebih rendah 0.58 dibandingkan pada kelompok kontrol. Bahkan setelah diberi pembebatan perineum selama 3 hari (Post test 2) maka rata rata rentang nyeri perineum kelompok perlakuan lebih rendah 1.35 dibandingkan pada kelompok kontrol. Data tersebut menunjukkan bahwa ada perbedaan yang cukup signifikant antara rata rata nyeri kelompok perlakuan dan kontrol, yang membuktikan bahwa bebat perineum efektif untuk mengurangi nyeri luka perineum ibu nifas.

\section{PEMBAHASAN}

Dari hasil uji deskriptif statistik dapat diketahui bahwa nilai rata-rata nyeri luka perineum pada ibu post partum kelompok perlakuan sebelum di beri bebat perineum adalah 4.77. Nilai rata-rata nyeri perineum pada ibu post partum setelah di beri satu hari pembebatan perineum (post test 1) adalah 2.75 sedangkan nilai rata rata post test ke 2 adalah 0.58 . Trend nilai menunjukkan penurunan dari 4.77 menjadi 2.75 pada post test 1 dan menjadi 0.58 pada post test 2 membuktikan bahwa ada penurunan nyeri perineum pada ibu post partum setelah diberi bebat perineum. Hal tersebut didukung dari hasil uji Wilxocon antara data pre test dan post test 1 yang menunjukkan $\mathrm{p}$ value $=$ 0.001 , dimana $\mathrm{p}<0.05$ yang berarti ada perbedaan yang signifikan antara rentang nyeri perineum ibu post partum sebelum di beri pembebatan dengan setelah diberi satu hari pembebatan. Selain itu juga didukung dengan hasil uji Wilxocon antara data post test 1 dan post test 2 yang menunjukkan $\mathrm{p}$ value $=0.001$, dimana $\mathrm{p}<$ 0.05 yang berarti ada perbedaan yang signifikan antara rentang nyeri perineum ibu post partum setelah diberi bebat perineum selama satu hari dengan setelah diberi tiga hari pembebatan, sehingga dapat disimpulkan bahwa bebat perineum efektif untuk mengurangi nyeri luka perineum ibu post partum.

Hasil penelitan tersebut sesuai dengan teori yang dikemukakan oleh Kurniati (2015) bahwa bebat perineum/ kempitan memiliki tujuan untuk menahan luka perineum dari gerakan dan gesekan; memberi tekanan terhadap: kecenderungan timbulnya perdarahan atau hematom, adanya ruang mati pada luka perineum; melindungi perineum yang cedera/ luka; memberikan support 
terhadap perineum yang cedera/luka serta memberikan tekanan pada luka perieum. Selain itu bebat perineum/ kempitan memiliki manfaat yaitu digunakan untuk membantu menghentikan perdarahan, mengurangi terjadinya pembengkakan, mengurangi nyeri dan mendukung bagian otot yang terluka pada perineum supaya menyatu kembali.

Pada penelitian ini, ibu post partum yang pada luka perineumnya diberi bebat/ kempitan merasa lebih nyaman karena pada saat ibu nifas melakukan gerakan/ mobilisasi, luka perineumnya tidak tergesek sehingga mengurangi nyeri saat beraktivitas/ bergerak. Fenomenanya, ibu post partum dengan luka perineum biasanya akan takut bermobilisasi karena ketika lukanya tergesek saat bergerak, luka tersebut akan terasa sangat nyeri. Selain itu dengan dicegahnya perdarahan dan pembengkaan pada luka perineum oleh bebat/ kempitan, akan menurunkan nyeri luka perineum dan bahkan mungkin akan mempercepat proses pemulihan luka.

Pada kelompok kontrol yang hanya diberi perawatan luka perineum biasa tapi tanpa diberikan bebat perineum sebenarnya juga mengalami penurunan nyeri luka perineum tetapi hasilnya tidak se-efektif jika dibandingkan dengan kelompok perlakuan karena bebat perineum telah dibuktikan dapat membantu mengurangi nyeri luka perineum jika ditambahkan sebagai penanganan pada luka perineum selain dari perawatan luka yang sudah biasa digunakan, misalnya: perawatan luka dengan medikasi dan dengan salep.

\section{KESIMPULAN DAN SARAN}

Berdasar hasil analisis data dan pembahasan dapat disimpulkan sebagai berikut: 1) Ada perbedaan rerata skor nyeri luka perineum ibu post partum sebelum dan sesudah 1 hari menggunakan bebat perineum. Rerata skor nyeri luka perineum ibu post partum sesudah 1 hari menggunakan bebat perineum lebih rendah dibandingkan sebelum menggunakan pembebatan. 2) Ada perbedaan rerata skor nyeri luka perineum ibu post partum setelah 1 hari dan setelah 3 hari menggunakan bebat perineum. Rerata skor nyeri luka perineum ibu post partum sesudah 3 hari menggunakan bebat perineum lebih rendah dibandingkan setelah 1 hari menggunakan pembebatan. 3) Ada perbedaan rerata skor nyeri luka perineum pada kelompok kontrol.

4) Ada perbedaan rerata skor nyeri luka perineum pada kelompok kontrol dan kelompok perlakuan dimana kelompok perlakuan yang diberi bebat perineum mengalami penurunan nyeri luka yang lebih signifikan dibanding pada kelompok kontrol.

Saran yang diajukan yaitu:

1) Bagi Masyarakat (Khususnya ibu post partum): para ibu post partum lebih aktif bertanya dan mencari informasi tentang penanganan nyeri luka perineum dan menerapkan penanganan tersebut, khususnya tentang bebat perineum.

2) Bagi petugas kesehatan

Petugas kesehatan khususnya Bidan diharapkan dapat menerapkan penanganan nyeri luka perineum dengan menggunakan penanganan perawatan luka perineum yang biasa digunakan ditambah dengan penganan menggunakan bebat perineum (kempitan).

3) Bagi institusi pendidikan bidan khususnya Poltekkes Kemenkes Surakarta supaya menambah buku-buku (referensi) tentang pembebatan luka perineum. 


\section{DAFTAR RUJUKAN}

Kurniati, Anna. 2015. Modul: Penanganan

Luka/Cidera. Jakarta:

Pusdiklatnakes PPSDM.

Mochtar, Rustam. 2008. Sinopsis Obstetri. Jakarta : EGC

Potter dan Perry. 2006. Buku Ajar Fundamental Keperawatan : Konsep, Proses, dan Praktek edisi 4 vol 1. Jakarta : EGC.

Oxorn, Harry. (2003). Ilmu Kebidanan: Patologi dan Fisiologi Persalinan. Human Labor and Birth. Jakarta : Yayasan Essentia Medica

Saifuddin. 2010. Buku Panduan Praktis Pelayanan Kesehatan Maternal dan Neonatal. Jakarta : EGC.

Saleha, S. 2009. Asuhan Kebidanan pada Masa Nifas. Jakarta : Salemba Medika.

Suherni. 2009. Perawatan Masa Nifas. Yogyakarta : Fitramaya. 